\title{
TESTS OF ALTERNATIVE REDUCTANTS IN THE SECOND URANIUM PURIFICATION CYCLE
}

\author{
M. C. THOMPSON
}

\section{TIS FILE}

RFCORD COPY

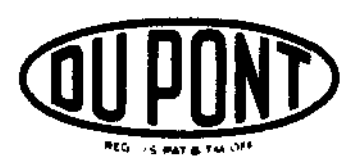

E. I. du Pont de Nemours \& Co. Savannah River Laboratory

Aiken, SC 29808 


\section{DISCLAIMER}

This report was prepsred as an account of work spansored by the United States Government. Neither the United Statue nor the United Stetes D. pertment of Eneroy, nor any of their employees, make any warranty, expresa or implied, or sssumes any legal lisbllity or responsibility for the accuracy, completeness, or usefulness of any information. apparatus, product, or process disclosed, or represents that its use would not infringe privately owned rights. Reference herein to any specific commerclal product, process, or service by trada name, mark, manufacturer, or otharwise does not necesearily constitute or imply its endorsement, recommendation, or fevoring by the United States Government or any agancy thereof. The views and opinions of euthors expressed herein do not necessarlly state or reflect those of the United States Government or any agency thereof.

Printed in the United States of Americe

Available from

National Technical Information Service

U. S. Department of Commerce 5285 Port Royal Road

Springfield, Virginia 22161

Price: Printed Copy A02; Microfiche AO1 


\section{DP-1548}

Distribution Category: UC-10

\section{TESTS OF ALTERNATIVE REDUCTANTS \\ IN THE SECOND URANIUM PURIFICATION CYCLE}

by

M. C. THOMPSON

Approved by:

J. D. Spencer, Research Manager

Fuel Cycle Technology Division

Publication Date: May 1980.

E. I. du Pont de Nemours \& Co. Savannah River Laboratory

Aiken, SC 29808

PREPARED FOR THE U. S. DEPARTMENT OF ENERGY UNDER CONTRACT DE.ACO9-76SRO0001 


\section{ABSTRACT}

Miniature mixer-settler tests of the second uranium purification cycle show that plutonium cannot be removed by hydroxylaminehydrazine $\left(\mathrm{NH}_{2} \mathrm{OH}-\mathrm{N}_{2} \mathrm{H}_{4}\right)$ because the acidity is too high, or by 2,5-di-t-pentylhydroquinone because $\mathrm{HNO}_{3}$ oxidizes the hydroquinone. Plutonium can be removed satisfactorily when U(IV)-hydrazine is used as the reductant. 


\section{CONTENTS}

Introduction 5

Hydroquinone Reductant 6

Hydroxylamine Nitrate 6

Uranium(IV) Reductant 11

Experimental Procedures 14

References 15 


\section{LIST OF FIGURES}

1 Second Uranium Cycle 5

2 Plutonium Distribution in 1D Mixer-Settler During

Tests with 2,5-di-t-pentylhydroquinone 7

3 Plutonium in Waste from the Second Uranium Cycle 9

4 Plutonium Distribution Coefficients and Aqueous $\mathrm{HNO}_{3}$ Concentrations in Second Uranium Cycle Tests with Hydroxylamine 10

5 Aqueous Nitric Acid Concentrations in Miniature Mixer-Settler Tests of Second Uranium Cycle with Uranium(IV) 12

6 Plutonium Distribution in Miniature Mixer-Settler Tests of Second Uranium Cycle with Uranium(IV)

Reductant 13

\section{LIST OF TABLES}

1 Miniature Mixer-Settler Tests with Hydroxylamine 8

2 Conditions of Tests with U(IV) in Second Uranium Cycie 11

3 PIutonium Removal in Tests with U(IV) 


\section{INTRODUCTION}

The second uranium cycle to purify uranium from first cycle operations is a well-proven solvent extraction process at the Savannah River Plant and other nuclear fuel reprocessing plants. The cycle (Figure 1) removes residual plutonium and fission products so the uranium can be recycled into fuel rods and returned to the reactor. Most existing processes use ferrous sulfamate as the reductant to separate plutonium from uranium. Ferrous sulfamate decomposes to ferric ion (Reaction 1) and sulfate ion (Reduction 2), which increase the volume of solid waste and the corrosiveness of liquid waste.

$$
\begin{aligned}
& \mathrm{Fe}^{2+}+\mathrm{Pu}^{4+} \rightarrow \mathrm{Fe}^{3+}+\mathrm{Pu}^{3+} \\
& \mathrm{HNO}_{2}+\mathrm{NH}_{2} \mathrm{SO}_{3}^{-} \rightarrow \mathrm{N}_{2}+\mathrm{SO}_{4}^{-}+\mathrm{H}_{2} \mathrm{O}
\end{aligned}
$$

A reductant that does not increase waste volume or corrosiveness is desirable for use in a commercial reprocessing plant. Hydroxylamine nitrate (HAN), U(IV), and 2,5-di-t-pentylhydroquinone have been tested as alternative reductants for plutonium. Hydrazine was added in all tests to react with nitrous acid.

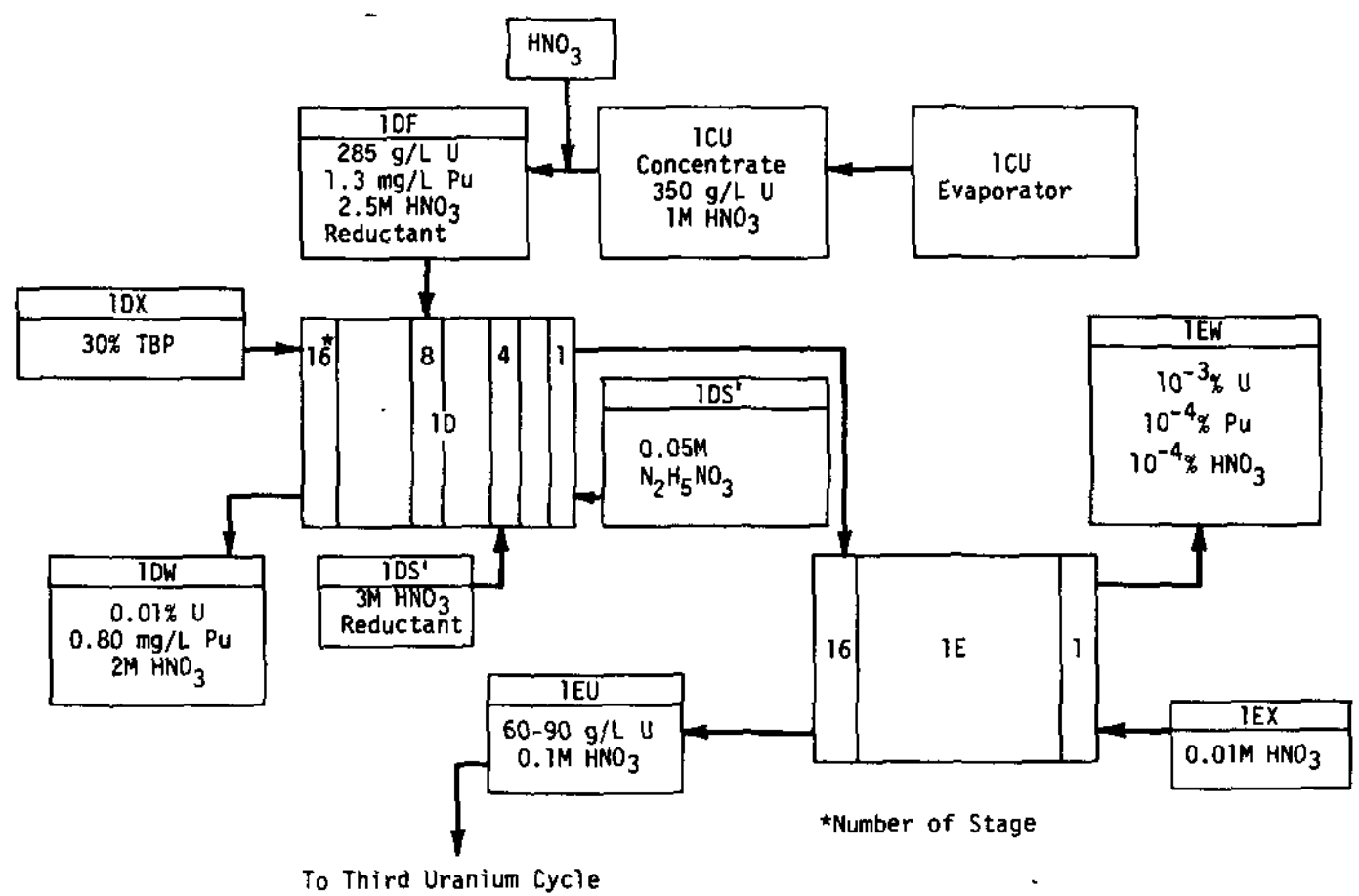

FIGURE 1. Second Uranium Cycle 


\section{Hydroquinone Reductant}

A variety of organic soluble hydroquinones have been used to reduce plutonium ${ }^{1,2,3,4}$ but reports on their use conflict on whether the reduction can be carried out in the presence of nitric acid in the organic phase. These hydroquinones are only soluble in the organic phase, so the resulting quinone could be reduced and recycled for the process.

Two miniature mixer-settler tests were made with 2,5-di-tpentylhydroquinone. * In the first test, $0.005 \mathrm{M}$ hydroquinone was in the extractant (1DX) and $U .01 \mathrm{M}$ hyarazine nitrate was in the scrub (IDS). After an initial period of normal operation, the yellow quinone color appeared in the extraction section of the mixer settler. In the second test, $0.05 \mathrm{M}$ hydroquinone was in the 1DX and $0.10 \mathrm{M}$ hydrazine nitrate was in the 1DS. Operation was the same as in the first test. No decontamination was obtained in either test; however, Figure 2 shows there was a difference in plutonium distribution coefficient for the mixersettler. Some reductant must have been present in the second test because the distribution coefficients are generally lower, causing plutonium to reflux to a higher concentration.

Batch tests in which $1 \mathrm{M}$ nitric acid-0.05M hydrazine solutions were contacted with $30 \%$ tri-n-butyl phosphate (TBP) in n-paraffin containing $0.05 \mathrm{M} 2,5-\mathrm{di}$-t-pentylhydroquinone showed rapid oxidation after an initial induction period. These tests confirm previous studies at ORNL showing that nitric acid in the organic phase oxidized the hydroquinone ${ }^{1,2}$. Therefore, hydroquinones cannot be used in the second uranium cycle to reduce plutonium.

\section{Hydroxylamine Nitrate}

Hydroxylamine nitrate or hydroxylamine-hydrazine mixtures has been shown to be an effective reductant in several studies. ${ }^{5,6}$ Hydroxylamine is a desirable reductant because after use it can be converted to gases and water by reaction with nitric acid (Reaction 3).7,

$$
4 \mathrm{NH}_{3} \mathrm{OH}^{+}+2 \mathrm{HNO}_{3} \rightarrow 3 \mathrm{~N}_{2} \mathrm{O}+7 \mathrm{H}_{2} \mathrm{O}+4 \mathrm{H}^{+}
$$

Hydroxylamine reduction of plutonium is highly dependent on the acidity of the solution (Reaction 4 ). ${ }^{5}, 6,9$

$$
2 \mathrm{NH}_{2} \mathrm{OH}^{+}+2 \mathrm{PU}^{4+} ₹ 2 \mathrm{Pu}^{3+}+\mathrm{N}_{2}+4 \mathrm{H}^{+}+2 \mathrm{H}_{2} \mathrm{O}
$$

\footnotetext{
* Sample obtained courtesy of Monsanto Co., which sells it as a rubber antioxidant under the trademark Santovan $A$.
} 


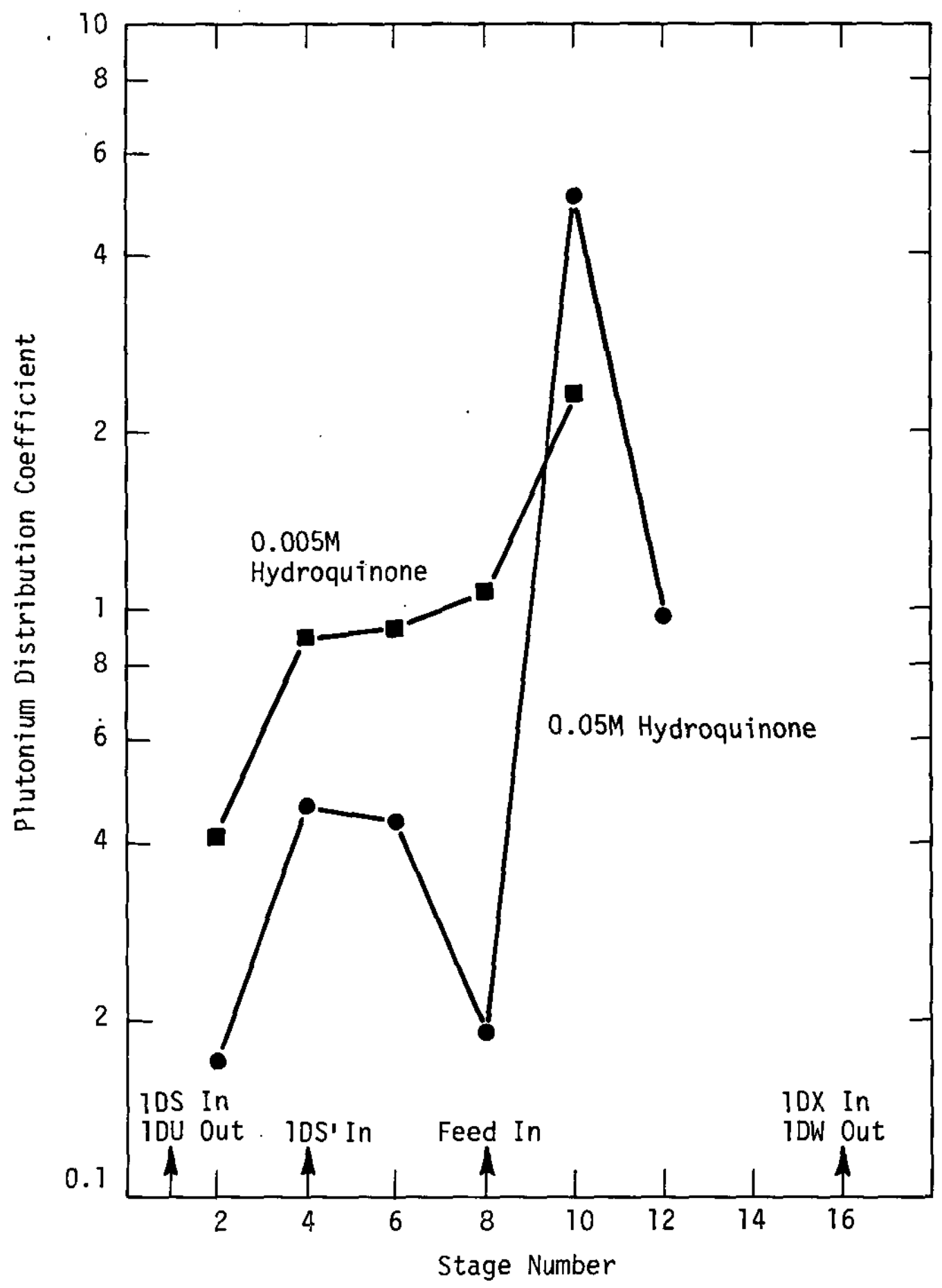

FIGURE 2. Plutonium Distribution in 10 Mixer-Settler During Tests with 2,5-di-t-pentylhydroquinone 
Thus, the rate of reduction is rapidly decreased by small changes in acidity. It was assumed that if hydroxylamine was added to the water scrub, plutonium would be reduced in stages with low acidity. Hydrazine added at the same point would prevent reoxidation of $\mathrm{Pu}^{3+}$ to $\mathrm{Pu}^{4^{+}}$, and plutonium would not re-extract. A number of miniature mixer-settler tests were made to determine the decontamination attainable. Table 1 shows conditions used in the tests.

In Test 1, uranium strip (1EX) flow was varied four days to vary the uranium concentration in the $1 E U$ between 60 and $90 \mathrm{~g} / \mathrm{L}$. Uranium losses to the $1 \mathrm{DW}$ varied from $<6 \times 10^{-4 \%}$ to $0.013 \%$ and averaged $3.5 \times 10^{-3} \%$.

Hydroxylamine-hydrazine reductant was ineffective at the concentration used in this test. Plutonium was not rejected to waste (1DW). Figure 3 shows plutonium in waste as a percent of plutonium in the feed during the test. At the start of the test, plutonium increased as expected but then peaked and decreased. The decontamination factors for the uranium product followed the same trend, going as high as 4.4 before dropping to 1.3 .

TABLE 1

Miniature Mixer-Settler Tests with Hydroxylamine

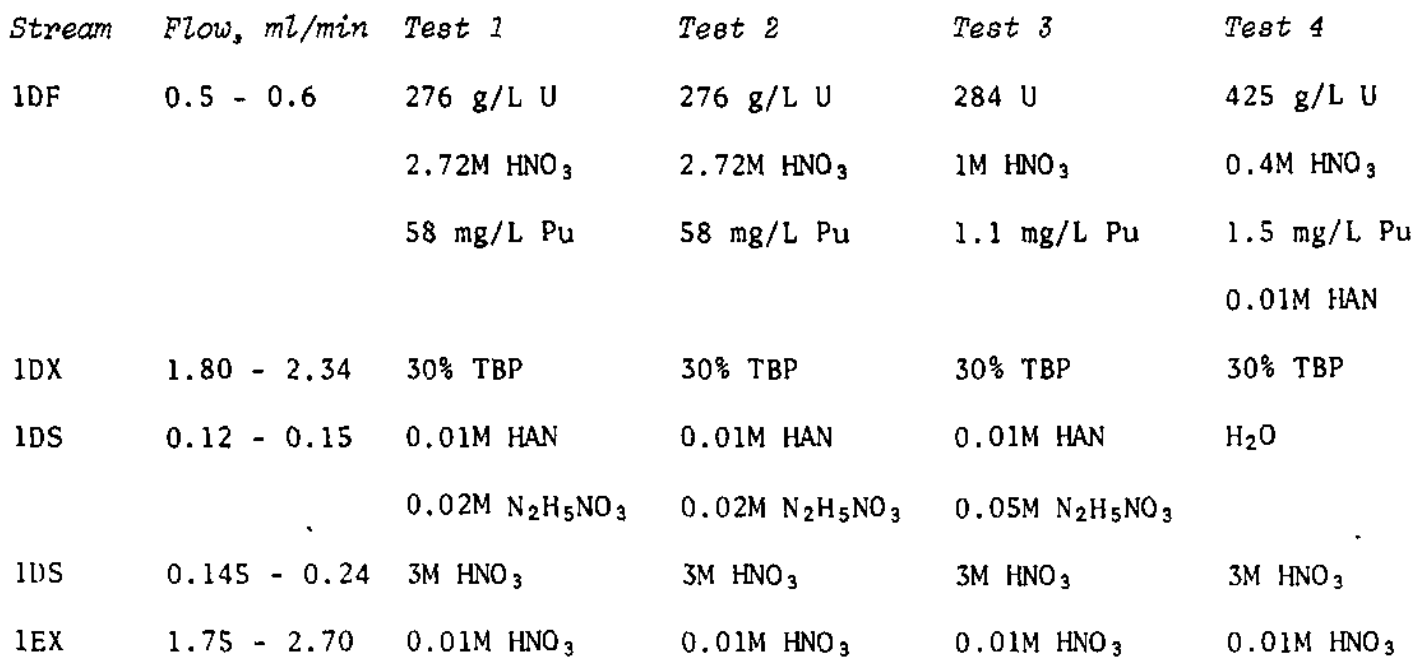




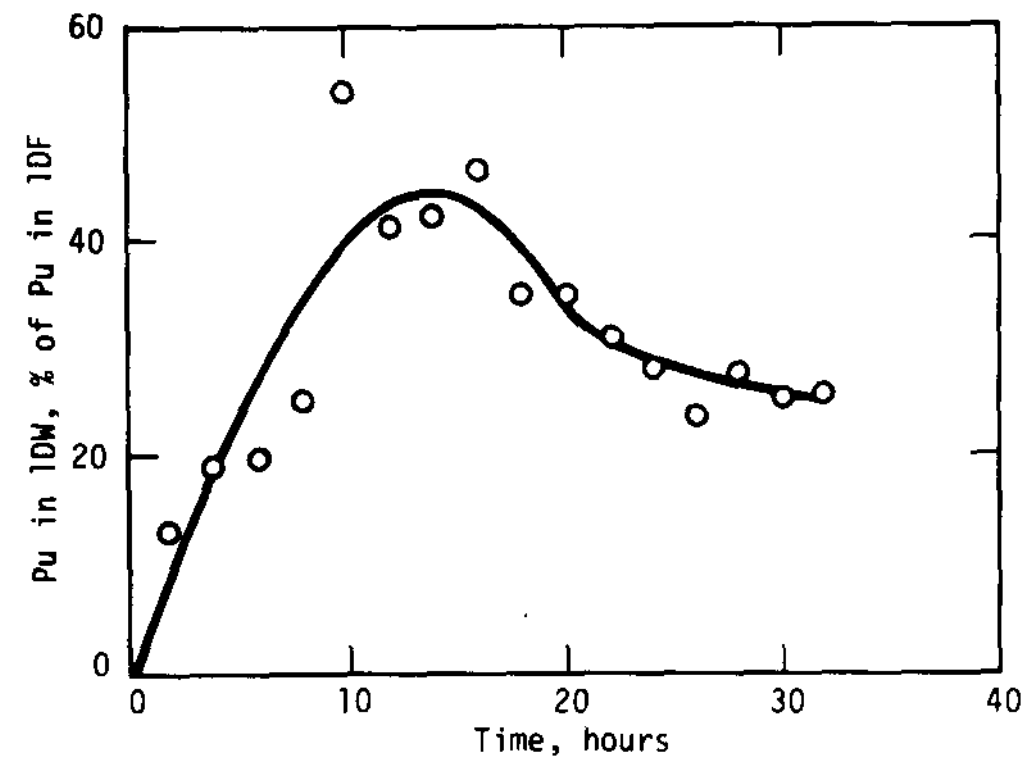

FIGURE 3. Plutonium in Waste from the Second Uranium Cycle

In Test 2 the procedure was repeated, and some stages in the 1D mixer-settler were sampled. Figure 4 shows the plutonium distribution coefficient and the aqueous nitric acid concentrations. The plutonium is reduced from $\mathrm{Pu}^{4+}$ to $\mathrm{Pu}^{3+}$ at $10 \mathrm{w}$ acidity and reoxidized at high acidity. Thus, plutonium refluxes until steady state is reached. In this case, steady state was reached with $75 \%$ of the plutonium in the product (1EU) and $25 \%$ in the waste (IDW). Plutonium reoxidized because the hydrazine-holding reductant was insufficient at the plutonium concentration in the test, which was $~ w 50$ times that in the normal flowsheet.

Test 3 had nearly the normal plutonium concentration, used more hydroxylamine, and was made with lower acid in the feed. The decontamination factors were higher, but varied from only 5 to 30 . The improvement is due to decreased acidity and a higher ratio of reductant to plutonium (300 to 1).

Test 4 had lower acid in the feed, higher uranium concentration, and hydroxylamine in the feed. The hydroxylamine was added 16-18 hours before the test to allow plenty of time for plutonium reduction. There was no decontamination from plutonium because the plutonium was reoxidized in the mixer-settler by nitric acid.

Since these tests gave very little promise of high decontamination, testing was discontinued. 


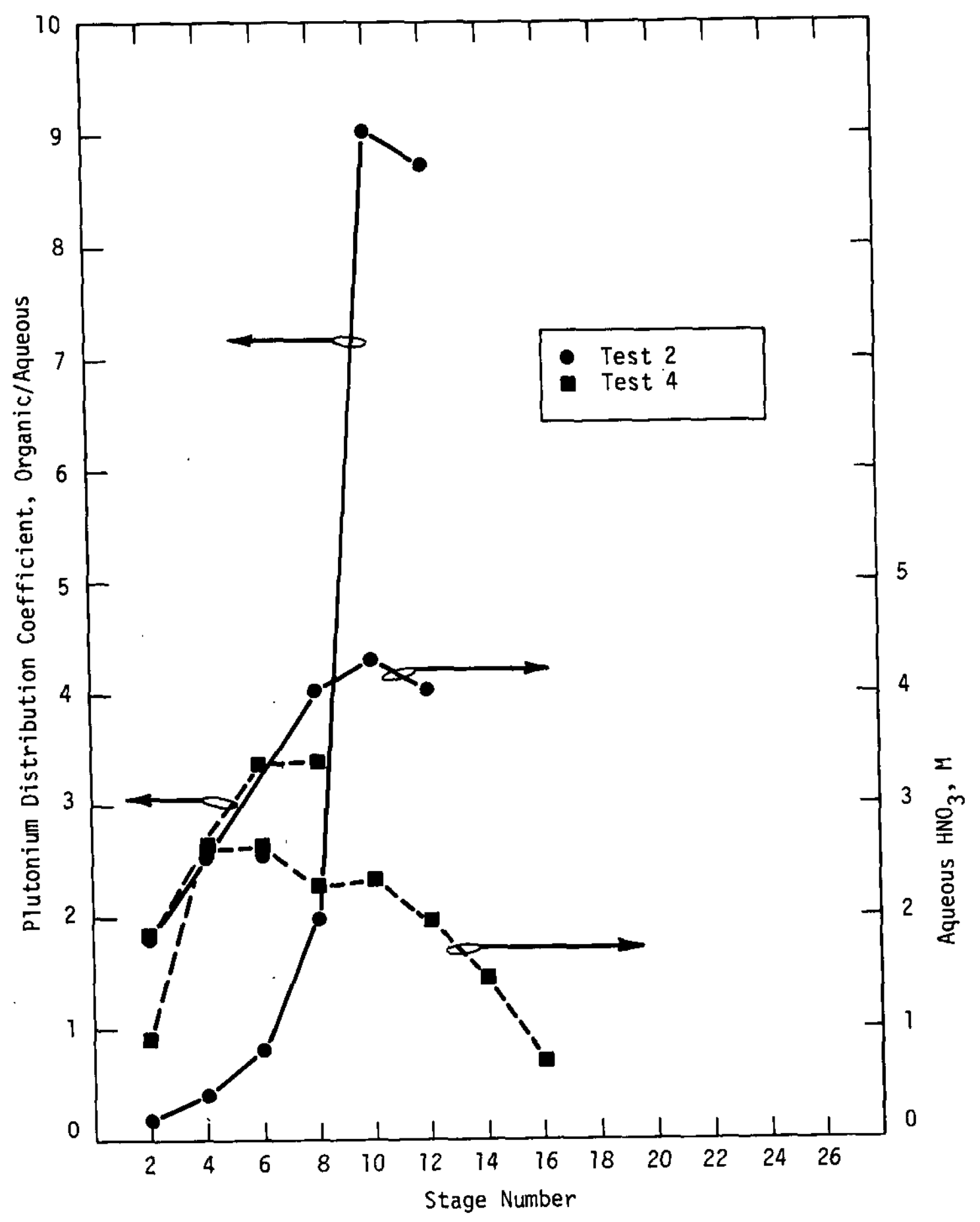

FIGURE 4. Plutonium Distribution Coefficients and Aqueous $\mathrm{HNO}_{3}$ Concentrations in Second Uranium Cycle Tests with Hydroxylamine 
Uranium(IV) Reductant

Uranium(IV) is an effective reductant for plutonium and is extractable so that no metal ion goes to the waste. ${ }^{10}$ Three miniature mixer-settler tests were made with U(IV) (Table 2). The decontamination factors were different in each test (Tabie 3). These tests show that U(IV) with hydrazine can be substituted for ferrous sulfamate in the second uranium cycle.

TABLE 2

Conditions for Tests with U(IV) in Second Uranium Cycle

\begin{tabular}{|c|c|c|c|c|c|}
\hline Stream & Stage & Relative Flow & Test 1 & Test 2 & Test 3 \\
\hline $10 F^{a}$ & 8 & 100 & None & $0.001 \mathrm{M} \mathrm{U}(\mathrm{IV})$ & None \\
\hline $10 X$ & 16 & 300 & $30 \%$ TBP & $30 \%$ TBP & $30 \%$ TBP \\
\hline $10 S$ & 1 & 20 & $\mathrm{H}_{2} \mathrm{O}$ & $\begin{array}{l}0.05 \mathrm{M} \mathrm{N}_{2} \mathrm{H}_{4}, \\
0.05 \mathrm{HNO}_{3}\end{array}$ & $\begin{array}{l}0.05 \mathrm{M} \mathrm{N}_{2} \mathrm{H}_{4}, \\
0.05 \mathrm{HNO}_{3}\end{array}$ \\
\hline 1DS & 4 & 40 & $\begin{array}{l}3 \mathrm{M} \mathrm{HNO}_{3}, 0.01 \mathrm{M} \\
\mathrm{U}(\mathrm{IV}), 0.15 \mathrm{M} \mathrm{N} \mathrm{H}_{2} \mathrm{H}_{4}\end{array}$ & Same & Same \\
\hline IDR & 9 & 7 & None & None & $\begin{array}{l}0.01 \mathrm{M} \mathrm{U}(\mathrm{IV}) \\
0.05 \mathrm{M} \mathrm{N}_{2} \mathrm{H}_{4}, \\
1 \mathrm{M} \mathrm{HNO}_{3}\end{array}$ \\
\hline
\end{tabular}

a. $1 D F$ also contained $272 \mathrm{~g} / \mathrm{L} \mathrm{U}, 2.5 \mathrm{M} \mathrm{HNO}_{3}$, and $100 \mathrm{mg} / \mathrm{L} \mathrm{Pu}$.

TABLE 3

Plutonium Removal in Tests with U(IV)

$\begin{array}{lll}\text { Test } & \text { Fu/U(IV) } & \begin{array}{l}\text { Decontomination } \\ \text { Factor }\end{array} \\ 1 & 1.9 & >30 \\ 2 & 5.4 & 1320 \\ 3 & 5.1 & 82\end{array}$


Only in Test 2, when U(IV) was in the feed, was the decontamination factor acceptable. Putting U(IV) in the feed allows time for complete reduction of plutonium. In the other tests, reduction was either not complete or reoxidation occurred after extraction of U(IV). Figure 5 shows that the aqueous $\mathrm{HNO}_{3}$ concentrations were similar in all three tests. The low value in Stage 8 of Test 3 is probably a bad analysis. Since the acid profiles are similar, the differences in plutonium distribution coefficient shown in Figure 6 are attributed to differences in plutonium behavior.

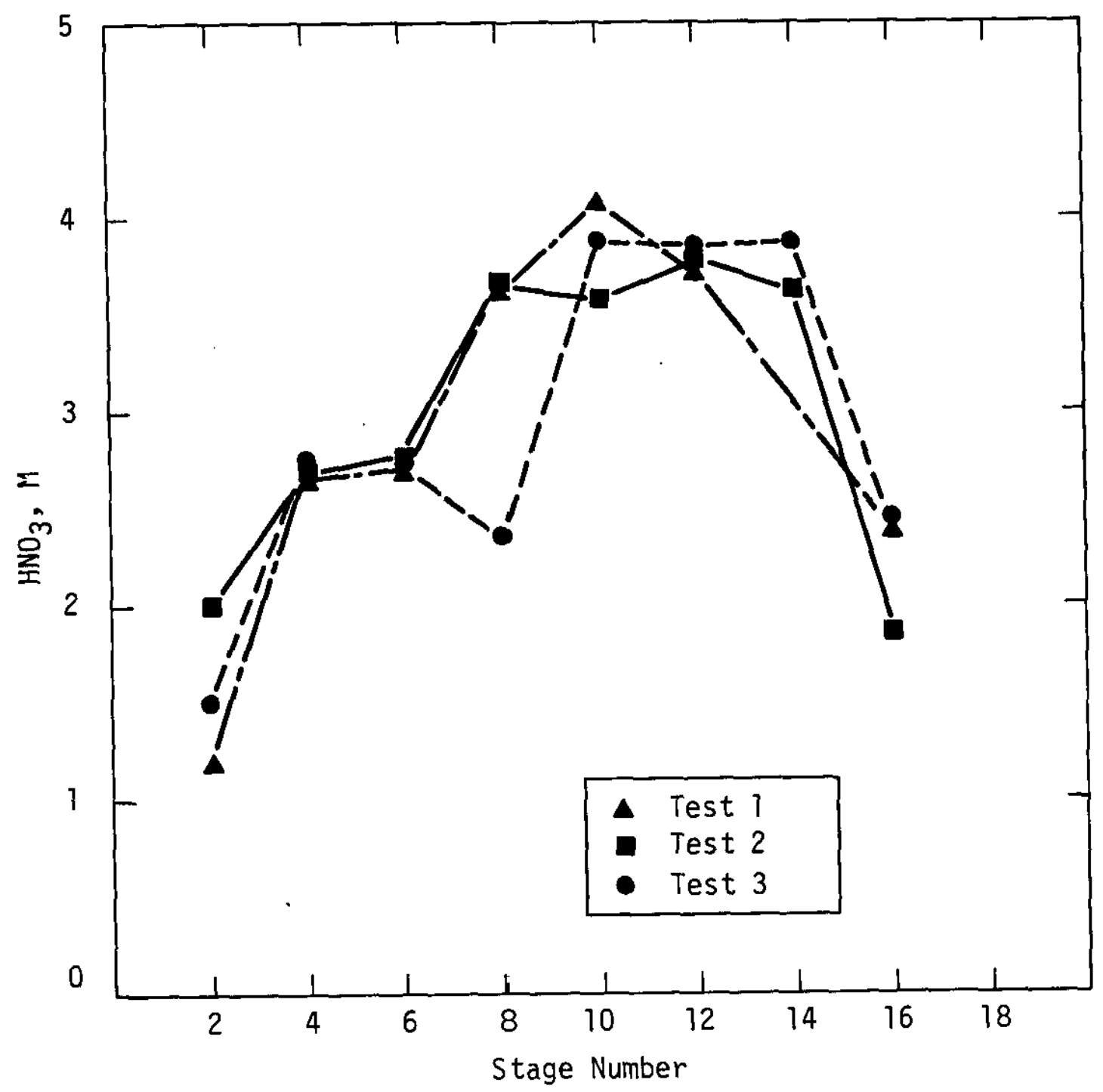

FIGURE 5. Aqueous Nitric Acid Concentrations in Miniature Mixer-Settler Tests of Second Uranium Cycle with uranium (IV) 


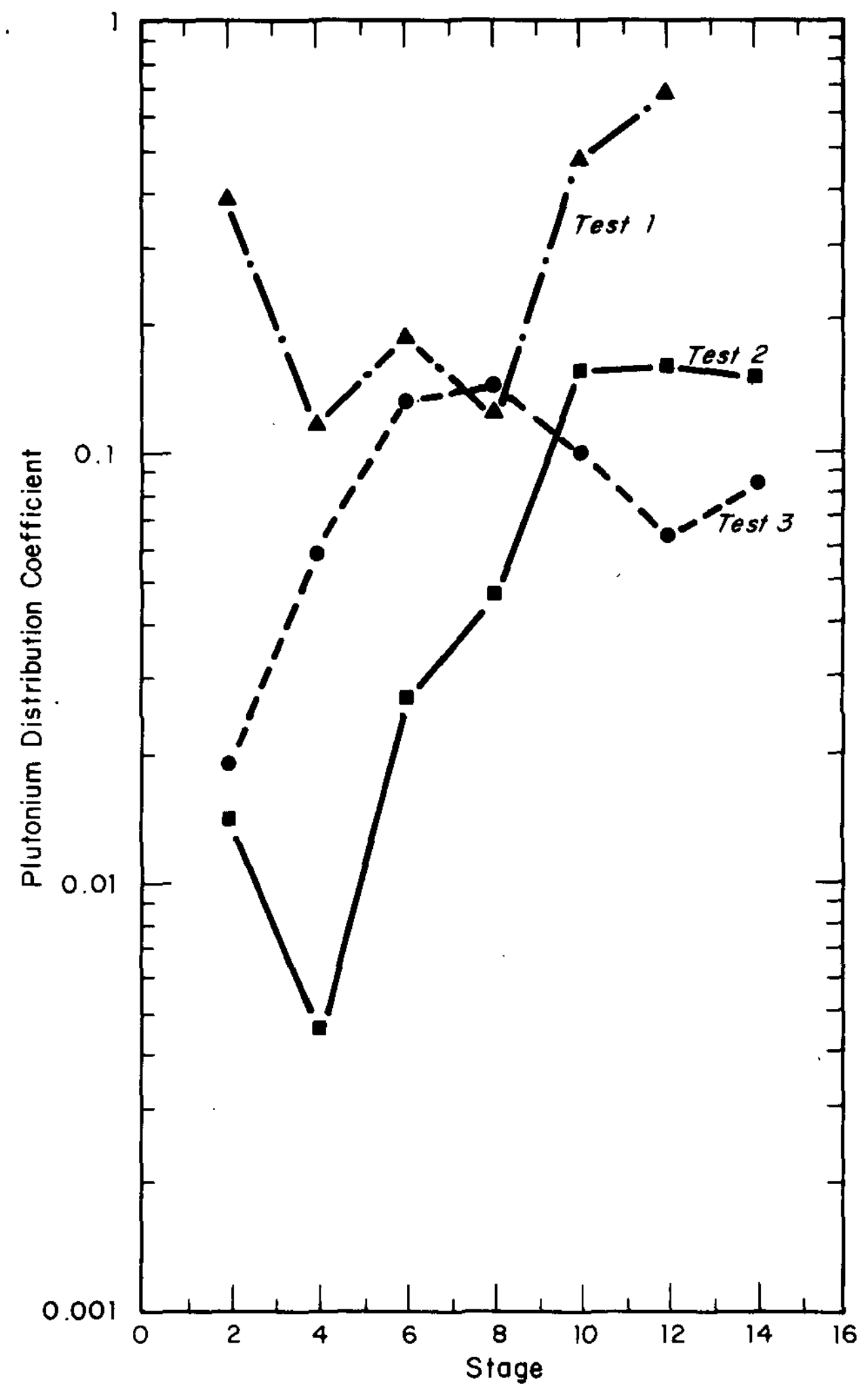

FIGURE 6. Plutonium Distribution in Miniature Mixer-Settler Tests of Second Uranium Cycle with Uranium(IV) Reductant 
The first test shows that hydrazine must be present in the scrub to prevent reoxidation of plutonium. In addition, insufficient U(IV) gave incomplete reduction even in Stage 4 where U(IV) was introduced. In the extraction section, $\mathrm{Pu(III)}$ was reoxidized because the distribution coefficient increased rapidly. In Test 2 , U(IV) in the feed completely reduced $\mathrm{Pu}^{4+}$ to $\mathrm{Pu}^{3+}$ before entering the mixer-settler. The additional $U(I V)$ in the acid scrub stream (1DS') and hydrazine in the scrub (IDS) maintained $\mathrm{Pu}^{3+}$ as shown by the low distribution coefficients throughout the mixer-settler. The decontamination factor is within a factor of 2-3 of that observed with ferrous sulfamate in similar tests. Test 3 shows that the additional $U(I V)$ in Test 2 compared to Test 1 was not responsible for the increased decontamination. The distribution coefficients are lower than in Test 1, but generally higher than in Test 2 .

\section{EXPERIMENTAL PROCEDURES}

Mixer-settler tests were made in a series of 16-stage miniature mixer-settlers described by Schlea, et a1. ${ }^{11}$ Uranium was determined by titration with the Davies and Gray method. ${ }^{1.2}$ Plutonium was determined by gross alpha and alpha pulse height analysis. Uranium(IV) was determined by reaction with excess ferric ion and subsequent titration of ferrous ion with ceric ion to a ferrous o-phenanthroline end point. Hydroxlamine was determined by reaction with excess ferric ion and subsequent potentiometric titration of ferrous ion formed in the reaction with dichromate. Nitrite was determined by reaction with excess ceric ion and titration of excess ceric with ferrous ion to a ferrous o-phenanthroline end point.

Hydroxylamine nitrate was obtained as a 16 wt $\%$ solution from the Savannah River Plant. Diluent was also obtained from the plant and consisted of a mixture of $C_{12}$ to $C_{15} n$-paraffin hydrocarbons with an average molecular weight of 2190 . Diluent was mixed with reagent-grade 100 vo1:TBP to make $30 \pm 0.2$ vol $\%$ TBP solution. The 30 vol $\% \mathrm{TBP}$ was washed with $0.5 \mathrm{M}$ $\mathrm{Na}_{2} \mathrm{CO}_{3}$. All other chemicals were reagent grade and were used without further purification. 


\section{REFERENCES}

1. Chemical Technology Division Annual Progress Report for Period Ending May 31, 1968. USAEC Report ORNL-4272, Oak Ridge National Laboratory, Oak Ridge, TN, pages 103-105 (1962).

2. C. Coleman and B. S. Weaver. U. S. Patent $3,580,705$ (May 25, 1971).

3. A. D. Site and G. De Ange1is. "Redox-Extraction Chromatography. Interaction Between 2,5-Di-Tert-Pentylhydroquinone and Tri-n-Octylphosphine Oxide in Cyclohexane Solution, and Further Analytical Applications." AnaZ. Chem. Acta 87, 365 (1976).

4. G. Grossi. "Organic Soluble Hydroquinones as Reducing Agents for Plutonium and Neptunium and Utilization of Hydroxylamine Nitrate for the Stripping of Plutonium from Organic Solutions of Long-Chain Tertiary Amines." Proceedings of the International Solvent Extraction Conference, Vo1. 2, p 634, Canadian Institute of Mining \& Metallurgy, Toronto, Canada (1977).

5. G. L. Richardson and J. L. Swanson. Plutonium Partitioning in the Purex Process with Hydrazine-Stabilized Hydroxylamine Nitrate. ERDA Report HEDL-TME-75-31, Westinghouse Hanford Co., Hanford Engineering Laboratory, Richland, WA (1975).

6. M. S. Okamoto and M. C. Thompson. "Coprocessing Solvent Extraction Studies." Nuclear Tech. 43, 126 (1979).

7. J. M. McKibben and J. E. Bercaw. Hydroxylamine Nitrate as a Plutonium Reductant in the Purex Solvent Extraction Process. ERDA Report DP -1248 , E. I. du Pont de Nemours \& Co., Savannah River Laboratory, Aiken, SC (1971).

8. A. D. Kelmers and D. Y. Valentine. LWR Fuel Processing and Recycle Program Quarterly Report for Period July 1 to September 30, 1976. ERDA Report ORNL/TM-5660, Oak Ridge National Laboratory, Oak Ridge, TN (1976).

9. G. S. Barney. "A Kinetic Study of the Reaction of Plutonium(IV) with Hydroxylamine." Joumal of Inorganic Nuclear Chemistry 38,1677 (1976). 
10. W. Baxter and A. Naylor. "Uranium(IV) as a Process Reductant for Plutonium(IV)." Proceedings of International Solvent Extraction Conference, Ed. H. A. C. McKay, T. V. Healy, I. L. Jenkins, and A. Naylor, Macmillan, London (1965).

11. C. S. Schlea, M. R. Caverly, E. C. Horni, H. E. Henry, and W. J. Jenkins. A Miniature Pilot Plant for Processing Irradiated Nuclear Fuel. USAEC Report DP-757, E. I. du Pont de Nemours \& Co., Savannah River Laboratory, Aiken, SC (1962).

12. A. R. Eberle, M. W. Leoner, C. G. Goldbeck, and C. J. Rodden. Titrimetric Determination of Uranium in Products, Fuel, and Scrap Materials After Ferrous Ion Reduction in Phosphoric Acid, Part I. ERDA Report NBL-252, New Brunswick Laboratory, New Brunswick, NJ (1970). 